\title{
Características da carcaça e da carne de tourinhos terminados em confinamento, recebendo diferentes níveis de concentrado na dieta ${ }^{1}$
}

\section{Regis Luis Missioㄹ, Ivan Luiz Brondani ${ }^{3}$, Dari Celestino Alves Filho ${ }^{3}$, João Restle ${ }^{4}$, Miguelangelo Ziegler Arboitte ${ }^{5}$, Luciane Rumpel Segabinazzi ${ }^{6}$}

\author{
1 Financiado pelo CNPq \\ 2 Programa de Pós-graduação em Zootecnia-UFSM \\ ${ }^{3}$ Departamento de Zootecnia - UFSM. \\ ${ }^{4}$ UFG. \\ 5 IFET Catarinense - Campus Sombrio. \\ ${ }^{6}$ Graduação em Zootecnia - UFSM.
}

RESUMO - O objetivo neste experimento foi avaliar as características quantitativas e qualitativas da carcaça e da carne de tourinhos abatidos entre 14-16 meses de idade, alimentados com diferentes níveis de concentrado na dieta. Foram utilizados 16 bovinos mestiços Charolês-Nelore, não castrados, alimentados com 22, 40, 59 ou 79\% de concentrado na dieta, distribuídos inteiramente ao acaso, com quatro repetições por dieta. A idade e o peso médio inicial dos animais foram de 9,32 meses e 192,44 kg, respectivamente. Os animais foram abatidos ao atingirem $400 \mathrm{~kg}$ de peso vivo, em frigorífico comercial a $54 \mathrm{~km}$ do confinamento. A dieta fornecida foi isoproteica e o volumoso utilizado foi a silagem de milho. A maturidade fisiológica da carcaça diminuiu com o aumento de concentrado na dieta, enquanto a percentagem de traseiro da carcaça, a coloração e a textura da carne aumentaram linearmente com o nível de concentrado na dieta. O aumento dos níveis de concentrado na dieta não altera a maioria das características de carcaça, mas melhora o aspecto visual da carne.

Palavras-chave: cortes comerciais, marmoreio, palatabilidade, porcentagem de músculo, rendimento de carcaça

\section{Carcass and beef characteristics of young bulls finished in feedlot and fed diets with different concentrate levels}

\begin{abstract}
The objetive in this experiment was to evaluate carcass and beef quantitative and qualitative characterstics from young bulls, slaughtered at 14-16 months of age and fed diets containing different concentrate levels. It was used sixteen Charolais- Nellore crossbreed non-castrated young bulls and fed diets containing $22 ; 40 ; 59$ or $79 \%$ of concentrate. The animals were complete randomly distributed, with four replicates per diet. Initial age and body weight of the animals were 9.32 months and $192.44 \mathrm{~kg}$, respectively. The animals were slaugthered at $400 \mathrm{~kg}$ of body weight in a packing plant, $54 \mathrm{~km}$ away from the feedlot. The diet offered was isoproteic and the roughage used was corn silage. The carcass physiological maturity decreased as the concentrate in diet increased. The hindquarter percentage, beef color, and texture increased linearly as the level of concentrate in diet increased. Increase in the concentrate levels in the diet does not affect the majority of carcass characterstics, although it improves meat visual aspect.
\end{abstract}

Key Words: carcass yield, comercial cuts, marbling, muscle percentage, palatability

\section{Introdução}

O crescimento nas exportações agropecuárias brasileiras em 2008 consolidou a liderança do país como principal fornecedor de produtos alimentares para o bloco europeu. Desde 2003 o Brasil sobrepujou os EUA, até então os maiores exportadores para a União Europeia (UE). O aumento das exportações brasileiras é atribuído ao crescimento do número de fazendas habilitadas a exportar para a UE. No entanto, este fato tem causado desconforto aos produtores europeus, que utilizam artifícios como a má propaganda sobre a carne bovina brasileira para reconquistar seus mercados (Abiec, 2008).

Sabe-se que mercados importadores pagam principalmente pela qualidade do produto adquirido. Nesse sentido, as características da carcaça, como peso, rendimento, acabamento e conformação, são determinantes do preço obtido pela venda das carcaças. Por outro lado, características relacionadas à carne e de interesse do consumidor, como a cor (principal característica em 
prateleira que determina a compra), maciez, palatabilidade e suculência são importantes para fidelizar o consumidor e conquistar espaço no mercado nacional e internacional.

Com a intensificação da atividade pecuária, principalmente visando à redução da idade de abate, a prática de confinamento, associada a altos teores de concentrado na dieta, é cada vez mais utilizado no Brasil (Anualpec, 2006). Nesse sentido, algumas pesquisas têm sugerido que o aumento de concentrado na dieta melhora o rendimento de carcaça (Silva et al., 2002), o acabamento (Costa et al., 2005), a conformação (Vaz et al., 2005), a composição física (Gesualdi Jr. et al., 2000) e o rendimento dos cortes comerciais da carcaça (Ribeiro et al., 2001). Em estudos para características da carne, Vaz et al. (2005) verificaram melhora na maciez com o aumento de concentrado na dieta. No entanto, existe grande variação dos resultados presentes na literatura, assim como limitados trabalhos que avaliaram a qualidade da carne de tourinhos alimentados com diferentes níveis de concentrado na dieta.

Objetivou-se avaliar neste trabalho níveis crescentes de concentrado na dieta sobre as características da carcaça e da carne de tourinhos abatidos aos 14-16 meses de idade.

\section{Material e Métodos}

O trabalho de campo foi realizado no período de 30/7/2005 a 13/3/2006, no Laboratório de Bovinocultura de Corte do Departamento de Zootecnia da Universidade Federal de Santa Maria, localizado na latitude de $29^{\circ} 43^{\prime}$ Sul e longitude $53^{\circ} 42^{\prime}$ Oeste, na Depressão Central do Rio Grande do Sul.

Foram utilizados 16 bovinos machos não-castrados, pertencentes a um mesmo grupo de contemporâneos, desmamados precocemente, dos seguintes grupos genéticos (quatro animais de cada grupo): Charolês $(\mathrm{C})$, Nelore (N), $11 / 16 \mathrm{C} 5 / 16 \mathrm{Ne} 11 / 16 \mathrm{~N} 5 / 16 \mathrm{C}$. Os animais apresentaram, ao início do período experimental, idade e peso corporal médio de 9,32 meses e 192,44 kg, respectivamente. Foram confinados individualmente em baias cobertas de $12 \mathrm{~m}^{2}$, pavimentadas com concreto e providas com bebedouros regulados com torneira boia e comedouros individualizados. Os animais foram distribuídos inteiramente ao acaso nas seguintes dietas: animais alimentados com $20,40,60$ ou $80 \%$ de concentrado na dieta. No entanto, após a determinação dos teores reais de matéria seca dos alimentos, as dietas apresentaram $22,40,59$ ou $79 \%$ de concentrado. O volumoso utilizado foi silagem de milho do híbrido BRS - 3150, com $23 \%$ de grãos na matéria seca ensilada, cortado a $20 \mathrm{~cm}$ do solo. A dieta foi calculada para ser isoproteica com $12 \%$ de proteína bruta, estimando-se consumo de $3 \mathrm{~kg}$ de matéria seca/100 kg de peso corporal. Para a formulação da fração concentrada foram utilizados grão de milho moído, farelo de soja, farelo de trigo, sal, calcário calcítico, ureia, monensina sódica e sulfato de amônio (Tabela 1).

O teor de nutrientes digestíveis totais (NDT) foi calculado de acordo com a equação proposta por Weiss et al. (1992) e a energia digestível segundo NRC (1996), em que $1 \mathrm{~kg}$ de $\mathrm{NDT}=4,4 \mathrm{Mcal} / \mathrm{kg}$ de matéria seca (Tabela 1 ).

À medida que os animais chegaram ao peso predeterminado de abate $(400 \mathrm{~kg})$, foram abatidos em frigorífico comercial, localizado a $54 \mathrm{~km}$ de distância do confinamento. No dia anterior ao abate, os animais foram pesados após jejum de sólidos e líquidos de 14 horas. Após o abate, as carcaças foram identificadas, divididas ao meio, pesadas para determinação do rendimento de carcaça quente, lavadas e levadas ao resfriamento por 24 horas a $-2^{\circ} \mathrm{C}$.

Após o resfriamento, as carcaças foram novamente pesadas para determinar o rendimento de carcaça fria, e também avaliadas quanto à conformação e maturidade fisiológica (Muller, 1987). Realizaram-se também medidas relacionadas ao comprimento de carcaça: a partir do bordo anterior do púbis ao bordo anterior medial da primeira costela; espessura de coxão; comprimento de perna, desde a articulação tíbio-tarsiana até o bordo anterior do púbis; comprimento de braço, da articulação rádio-carpiana até a extremidade do olécrano; e perímetro de braço, envolvendo a parte média do rádio-cúbito e os músculos que recobrem a região.

A meia-carcaça esquerda foi separada nos cortes serrote - que corresponde à região posterior da carcaça, separado do dianteiro entre a quinta e a sexta costelas - além do costilhar que compreende pescoço, paleta, braço e cinco

Tabela 1 - Composição das dietas ofertadas com base da matéria seca

\begin{tabular}{lrrrr}
\hline Ingrediente (\%) & \multicolumn{4}{c}{ Nível de concentrado (\%) } \\
\cline { 2 - 5 } & \multicolumn{1}{c}{22} & \multicolumn{1}{c}{40} & \multicolumn{1}{c}{59} & \multicolumn{1}{c}{79} \\
\hline Silagem milho & 78,00 & 60,00 & 41,00 & 21,00 \\
Milho grão moído fino & 5,91 & 9,43 & 29,32 & 49,15 \\
Farelo soja & 3,52 & 4,11 & 2,57 & 0,32 \\
Farelo trigo & 10,57 & 24,27 & 24,79 & 26,97 \\
Calcário calcítico & 0,92 & 1,46 & 1,63 & 1,92 \\
NaCl & 0,33 & 0,32 & 0,32 & 0,32 \\
Ureia & 0,51 & 0,37 & 0,32 & 0,27 \\
Monensina sódica & 0,09 & 0,05 & 0,03 & 0,04 \\
Sulfato de amônio & 0,13 & 0,05 & 0,03 & 0,02 \\
Composição nutricional (\%) & & & & \\
Matéria seca & 39,47 & 50,06 & 61,00 & 71,73 \\
Proteína bruta & 11,20 & 12,50 & 12,10 & 11,80 \\
Nutrientes digestíveis totais & 65,30 & 66,70 & 70,60 & 74,20 \\
Energia digestível, Mcal/kg & 2,87 & 2,94 & 3,11 & 3,27 \\
Fibra em detergente neutro & 48,00 & 43,10 & 29,60 & 16,50 \\
Fibra em detergente ácido & 22,60 & 19,40 & 13,10 & 6,90 \\
\hline
\end{tabular}

R. Bras. Zootec., v.39, n.7, p.1610-1617, 2010 
costelas, a partir da sexta, mais músculos abdominais. Depois de separados, os cortes foram pesados para calcular a percentagem em relação à meia-carcaça.

Na meia-carcaça direita, foi retirada uma secção entre a 10-11-12 a costelas, conforme metodologia descrita por Hankins \& Howe (1946) e adaptada por Müller et al. (1973), na qual foi medida a espessura de gordura de cobertura e o grau de gordura intramuscular da carne (marmoreio) (Muller, 1987). Neste local ainda foram realizadas as avaliações referentes à coloração e textura da carne, de acordo com escala de 1 a 5 proposta por Muller (1987). Foi também desenhado o contorno do músculo longissimus dorsi, em papel vegetal, para posterior determinação de sua área, em mesa digitalizadora por meio de uso de software Site1.0.

Na secção de cada meia-carcaça direita, compreendendo a $10^{\mathrm{a}}, 11^{\mathrm{a}}$ e $12^{\mathrm{a}}$ costelas, foi efetuada a separação em músculo, gordura e osso, cujos pesos foram utilizados para estimar suas participações na carcaça, conforme Hankis \& Howe (1946). Posteriormente, o músculo longissimus dorsi da secção foi devidamente embalado e identificado, sendo congelado a $-18^{\circ} \mathrm{C}$. Após um mês de congelamento foram retirados, de cada porção do músculo, dois bifes com espessura de 2,5 cm cada, que foram pesados, identificados, colocados em bandejas de alumínio e levados para descongelamento em refrigerador, durante 12 horas, a $4^{\circ} \mathrm{C}$. Depois de descongelados, foram novamente pesados para obtenção da perda de peso, na forma de líquidos, durante o descongelamento.

Após este processo, os bifes foram colocados em bandejas individuais, previamente pesadas, e então assados em forno a gás, por 15 minutos, até que a temperatura interna atingisse $70^{\circ} \mathrm{C}$, monitorada por termômetro. Depois, foram novamente pesados, com e sem sua bandeja, para obtenção da perda de líquidos da carne durante o processo de cozimento.

Utilizou-se painel composto por seis pessoas treinadas em análise sensorial, que avaliaram a maciez, suculência e palatabilidade da carne. Para essas três avaliações utilizou-se escala de pontos de 1 a 9 (Muller, 1987). A maciez da carne também foi medida de forma objetiva, com o uso do aparelho Warner Bratzler Shear, utilizando o segundo bife assado de cada secção, onde se determinou a força necessária para o cisalhamento dos feixes de fibras da carne (média de seis análises por bife).

Os dados foram submetidos à análise de variância utilizando-se o procedimento GLM, com auxílio do programa estatístico SAS (1997). Foi realizado teste de normalidade nas características estudadas, sendo que quando não apresentavam comportamento normal foram ajustadas através do $\log ^{2}$. Foi realizado também teste de correlação e regressão polinomial. As análises foram realizadas de acordo com o seguinte modelo matemático geral:

$$
\mathrm{Y}_{\mathrm{ij}}=\mu+\mathrm{T}_{\mathrm{i}}+\varepsilon_{\mathrm{ij}}
$$

em que: $\mathrm{Y}_{\mathrm{ij}}=$ as variáveis dependentes; $\mu=$ média de todas as observações; $T_{i}=$ efeito dos tratamentos; e $\varepsilon_{i j}=$ erro experimental residual (erro b). Já para o estudo da regressão polinomial, foi utilizado o seguinte modelo:

$$
\mathrm{Y}_{\mathrm{ijk}}=\beta_{0}+\beta_{1} \mathrm{X}_{\mathrm{i}}+\mathrm{b}_{2} \mathrm{X}_{\mathrm{i}}^{2}+\alpha_{\mathrm{ijk}}+\varepsilon_{\mathrm{ijk}}
$$

em que: $Y_{\mathrm{ijk}}=$ variáveis-dependentes; $\beta$ 's $=$ coeficientes de regressão; $X_{\mathrm{ijk}}=$ variáveis independentes; $\alpha_{\mathrm{ijk}}=$ desvios da regressão; e $\varepsilon_{\mathrm{ijk}}=$ erro aleatório residual.

\section{Resultados e Discussão}

O aumento do nível de concentrado na dieta até 59\% possibilitou o abate de animais com menores idades (Tabela 2). A diminuição da idade de abate está relacionada ao aumento $(\mathrm{P}<0,01)$ do ganho de peso vivo médio diário com o incremento de concentrado na dieta. Os valores verificados, no presente estudo, para o ganho de peso vivo médio diário foram de 1,$05 ; 1,29 ; 1,40$ e 1,43 kg, para os níveis de concentrado 22, 40, 59 e $79 \%$, respectivamente. As demais características não diferiram entre os níveis de concentrado na dieta, já que a idade inicial e o peso inicial foram controlados para o início do experimento de campo e o peso de abate foi predeterminado em aproximadamente $400 \mathrm{~kg}$ de peso corporal.

Tabela 2 - Idade inicial e de abate, dias de confinamento, peso corporal inicial e de abate de bovinos alimentados com diferentes níveis

\begin{tabular}{|c|c|c|c|c|c|c|c|}
\hline \multirow[t]{2}{*}{ Item } & \multicolumn{4}{|c|}{ Nível de concentrado (\%) } & \multirow[t]{2}{*}{ EP } & \multirow[t]{2}{*}{ Média } & \multirow[t]{2}{*}{$\mathrm{P}$} \\
\hline & 22 & 40 & 59 & 79 & & & \\
\hline Idade inicial, meses & 9,45 & 8,85 & 9,52 & 9,45 & 0,40 & 9,32 & 0,61 \\
\hline Idade de abate, meses ${ }^{1}$ & 16,60 & 15,00 & 14,80 & 14,80 & 0,38 & 15,28 & 0,01 \\
\hline Dias de confinamento & 199,00 & 171,00 & 140,00 & 140,00 & - & - & - \\
\hline Peso corporal inicial, $\mathrm{kg}$ & 191,25 & 187,00 & 197,50 & 194,00 & 15,76 & 192,44 & 0,97 \\
\hline Peso de abate, $\mathrm{kg}$ & 400,75 & 407,25 & 392,75 & 394,75 & 30,21 & 398,88 & 0,99 \\
\hline
\end{tabular}
de concentrado na dieta

${ }^{1}$ Idade de abate $=16,79-0,0302 \mathrm{NC}, \mathrm{R}^{2}=0,51, \mathrm{P}<0,05, \mathrm{CV}=5,03$. 
Tabela 3 - Características quantitativas e qualitativas da carcaça de bovinos alimentados com diferentes níveis de concentrado na dieta

\begin{tabular}{|c|c|c|c|c|c|c|c|}
\hline Item & \multicolumn{4}{|c|}{ Nível de concentrado (\%) } & EP & Média & $\mathrm{P}$ \\
\hline Peso de carcaça quente, $\mathrm{kg}$ & 234,22 & 236,20 & 231,05 & 230,12 & 19,54 & 232,90 & 0,99 \\
\hline Rendimento de carcaça quente, $\%$ & 58,21 & 58,07 & 58,63 & 58,26 & 0,77 & 58,30 & 0,53 \\
\hline Rendimento de carcaça fria, $\%$ & 56,88 & 56,68 & 57,35 & 57,14 & 0,75 & 57,02 & 0,96 \\
\hline Quebra ao resfriamento, \% & 2,28 & 2,39 & 2,17 & 1,93 & 0,16 & 2,19 & 0,11 \\
\hline Área do longissimus dorsi, $\mathrm{cm}^{2}$ & 62,99 & 65,68 & 70,31 & 68,48 & 6,38 & 66,87 & 0,86 \\
\hline $\begin{array}{l}\text { Área do longissimus dorsi } / 100 \mathrm{~kg} \\
\text { de carcaça, } \mathrm{cm}^{2}\end{array}$ & 27,42 & 28,63 & 31,40 & 30,27 & 1,69 & 29,42 & 0,29 \\
\hline Conformação, pontos ${ }^{1}$ & 9,50 & 10,00 & 10,25 & 10,00 & 1,37 & 9,94 & 0,98 \\
\hline Maturidade fisiológica, pontos ${ }^{3}$ & 13,50 & 13,00 & 14,00 & 14,25 & 0,19 & 13,69 & $<0,01$ \\
\hline Perímetro de braço, cm & 33,50 & 31,00 & 32,00 & 29,50 & 1,96 & 31,50 & 0,55 \\
\hline
\end{tabular}

Maturidade fisiológica $=12,82+0,017 \mathrm{NC} ; \mathrm{R}^{2}=0,67 ; \mathrm{CV}=3,53$.

${ }^{1} 1$-3: inferior; 4-6: má: 7-9: regular; 10-12: boa; 13-15: muito boa; 16-18: superior; ${ }^{3} 1$-3: acima de 8 anos de idade; 4-6: de 5,5 a 8 anos de idade; 7-9: de 4 a 5,5 anos de idade; 10-12: de 2,5 a 4 anos de idade; 13-15: menos de 2,5 anos de idade

O peso de carcaça quente e fria e os rendimentos de carcaça quente e fria não foram influenciados $(\mathrm{P}>0,05)$ pelos níveis de concentrado (Tabela 3). Silva et al. (2002), estudando a inclusão de concentrado na dieta $(20,40,60 \mathrm{ou}$ $80 \%$ ) observaram que, no período de engorda dos animais, houve aumento linear no rendimento de carcaça, decorrente da diminuição linear no peso do trato gastrintestinal. O rendimento de carcaça, segundo Pattersson et al. (1995), é altamente influenciado pelo peso corporal do animal e pelo peso do trato gastrintestinal. Neste estudo, o peso do trato gastrintestinal vazio foi semelhante $(\mathrm{P}>0,05)$ para todos os níveis de concentrado $(15,36 ; 16,93 ; 19,06$ e $18,63 \mathrm{~kg}$, respectivamente), determinando valores semelhantes para o rendimento de carcaça entre os níveis de concentrado estudados (Tabela 3), uma vez que os animais foram abatidos com peso fixo de $400 \mathrm{~kg}$ aproximadamente. Restle et al. (2001) afirmaram que quando são utilizados volumosos com alta taxa de passagem não são encontradas diferenças no rendimento de carcaça entre animais alimentados com diferentes níveis de concentrado. Segundo Restle et al. (2000), o rendimento de carcaça também é influenciado pelo número de horas de jejum a que os animais são submetidos, pelo tipo de dieta e pelo grupo genético, entre outros.

Os pesos de carcaça fria obtidos em todos os níveis de concentrado situaram-se acima do mínimo estabelecido pelos frigoríficos $(220 \mathrm{~kg})$, o que pode ser creditado ao protocolo do experimento, em que se fixou o peso de abate em $400 \mathrm{~kg}$, e ao tipo racial utilizado, que se enquadra em um grupo genético mais tardio, mas que bem alimentado atinge peso e acabamento desejado, com ótimo rendimento de carcaça (Tabela 3). Para a categoria superjovem, no entanto, são comercializadas carcaças com menores pesos (acima de $180 \mathrm{~kg}$ ), principalmente devido à associação do baixo peso de carcaça com a idade dos animais, que têm influência significativa na maciez e coloração da carne (Muller, 1987), desde que as carcaças apresentem bom acabamento de gordura.

Muller (1987) afirmou que a espessura de gordura subcutânea (EGS) tem como principal função a proteção da carcaça contra a desidratação e escurecimento da parte externa dos músculos durante o resfriamento. Este mesmo autor recomendou para comparações desta característica que a espessura de gordura subcutânea fosse expressa em relação ao peso de carcaça, visto que carcaças com igual espessura de gordura subcutânea, mas com pesos superiores, apresentam maior rendimento de carne magra. Evidenciou-se que os níveis de concentrado não prejudicaram o acabamento das carcaças, já que a EGS e a EGS/100 kg de carcaça fria não foram afetadas $(\mathrm{P}>0,05)$, ficando acima do mínimo exigido pelos frigoríficos (3 mm). Brondani et al. (2004) verificaram interação entre genótipo e nível de energia, onde em nível alto de energia na dieta de animais Red Angus apresentaram maior espessura de gordura subcutânea, e em dietas com nível baixo de energia animais Hereford apresentaram maior espessura de gordura subcutânea, demonstrando sua maior precocidade.

Considerando que o ganho de peso médio diário do presente estudo respondeu de forma linear e crescente ( $\mathrm{Y}=0,966+0,0065 \mathrm{NC}, \mathrm{P}<0,01)$ ao incremento de concentrado na dieta, os resultados para espessura de gordura subcutânea não eram esperados, já que segundo o NRC (1996) maiores 
ganhos de peso corporal estão associados a maiores taxas de deposição de gordura. No entanto, verificou-se que com o peso de abate dos animais pré-estabelecido, o acabamento da carcaça não foi prejudicado, pois o maior tempo de confinamento para os animais que receberam menores níveis de concentrado na dieta pode ter compensado a menor taxa de deposição de gordura. A semelhança entre as espessuras de gordura subcutânea pode justificar a falta de diferença $(\mathrm{P}>0,05)$ para a quebra ao resfriamento (Tabela 3$)$ entre os níveis de concentrado na dieta, já que a gordura protege a carcaça contra a perda de líquidos (Muller, 1987).

As características referentes à musculosidade da carcaça não se alteraram $(\mathrm{P}>0,05)$ com os diferentes níveis de concentrado na dieta (Tabela 3). Foram verificadas correlações positivas $(\mathrm{P}<0,001)$ entre o peso de carcaça fria e a conformação $(0,75)$, comprimento de carcaça $(0,94)$, comprimento de perna $(0,63)$, perímetro de braço $(0,50)$ e percentagem de músculo na carcaça $(0,93)$. Estas correlações inferem que melhores conformações, em animais jovens e de raças continentais, podem ser alcançadas com maiores pesos de carcaça. Vaz et al. (2005), estudando $25 ; 35$ ou $45 \%$ de concentrado na dieta observaram alterações na conformação da carcaça, que aumentou com a elevação da fração concentrada na dieta. Por outro lado, Petit et al. (1994) estudando diferentes níveis de energia, afirmaram que diferenças nas características da carcaça são raras, quando os animais são abatidos com mesmo peso corporal.
A maturidade fisiológica, por sua vez, apresentou comportamento linear crescente com o incremento de concentrado na dieta, aumentando em média 0,017 pontos a cada $1 \%$ a mais de concentrado na dieta. Este resultado pode ser atribuído à diferença da idade de abate dos animais, a qual diminuiu com o aumento de concentrado na dieta, caracterizando animais mais jovens.

Os valores absolutos obtidos para os cortes traseiro, dianteiro, costilhar e os pesos relativos para dianteiro e costilhar não foram influenciados $(\mathrm{P}>0,05)$ pelos níveis de concentrado na dieta (Tabela 4). Da mesma forma, Ferreira et al. (1998) e Gesualdi Jr. et al. (2000), variando os níveis de concentrado na dieta para animais $\mathrm{F} 1$ europeu continental $\times$ zebu, não encontraram efeitos significativos sobre os cortes básicos da carcaça. Segundo Berg \& Butterfield (1979), o animal tende a manter, dentro de certos limites, equilíbrio entre os quartos traseiro e dianteiro (Tabela 3 ).

$\mathrm{O}$ interesse no aumento na participação percentual de traseiro na carcaça é importante para o sistema produtivo, principalmente para a cadeia frigorífica, uma vez que os principais cortes nobres e de melhores preços são encontrados nesta porção da carcaça. De outra forma, o aumento desta característica prova que a terminação de animais não castrados, desde que jovens, não apresenta necessariamente, aumento na porção dianteira da carcaça.

O nível de concentrado da dieta não influenciou $(\mathrm{P}>0,05)$ a composição física da carcaça nem a relação entre os

Tabela 4 - Peso absoluto e percentual de dianteiro, costilhar e traseiro da carcaça de bovinos alimentados com diferentes níveis de concentrado na dieta

\begin{tabular}{|c|c|c|c|c|c|c|c|}
\hline \multirow[t]{2}{*}{ Item } & \multicolumn{4}{|c|}{ Nível de concentrado $(\%)$} & \multirow[t]{2}{*}{ EP } & \multirow[t]{2}{*}{ Média } & \multirow[t]{2}{*}{$\mathrm{P}$} \\
\hline & 22 & 40 & 59 & 79 & & & \\
\hline Peso de carcaça quente, $\mathrm{kg}$ & 234,22 & 236,20 & 231,05 & 230,12 & 19,54 & 232,90 & 0,99 \\
\hline Costilhar, $\mathrm{kg}$ & 28,00 & 30,00 & 26,05 & 25,65 & 2,15 & 24,42 & 0,480 \\
\hline Traseiro, kg & 106,10 & 109,85 & 112,30 & 112,25 & 10,19 & 110,12 & 0,970 \\
\hline Dianteiro, \% & 19,98 & 19,77 & 19,75 & 20,00 & 0,40 & 19,88 & 0,900 \\
\hline
\end{tabular}

$1 \%$ de traseiro na carcaça $=22,48+0,032 \mathrm{NC} ; \mathrm{R}^{2}=0,57 ; \mathrm{CV}=2$.

Tabela 5 - Composição física e relação entre tecidos da carcaça de bovinos alimentados com diferentes níveis de concentrado na dieta

\begin{tabular}{|c|c|c|c|c|c|c|c|}
\hline \multirow[t]{2}{*}{ Item } & \multicolumn{4}{|c|}{ Nível de concentrado $(\%)$} & \multirow[t]{2}{*}{ EP } & \multirow[t]{2}{*}{ Média } & \multirow[t]{2}{*}{$\mathrm{P}$} \\
\hline & 22 & 40 & 59 & 79 & & & \\
\hline Músculo na carcaça, $\mathrm{kg}$ & 152,29 & 152,92 & 149,24 & 142,58 & 15,83 & 149,26 & 0,92 \\
\hline Gordura na carcaça, kg & 48,04 & 44,65 & 44,39 & 49,10 & 4,38 & 46,57 & 0,82 \\
\hline Osso na carcaça, kg & 30,62 & 34,14 & 33,45 & 34,53 & 3,00 & 33,19 & 0,82 \\
\hline Músculo, \% & 66,28 & 66,27 & 65,64 & 62,88 & 2,61 & 65,27 & 0,77 \\
\hline Gordura, \% & 21,19 & 19,34 & 19,97 & 22,03 & 1,81 & 20,63 & 0,72 \\
\hline Osso, \% & 13,42 & 14,87 & 14,84 & 15,30 & 0,84 & 14,61 & 0,44 \\
\hline Relação músculo/osso & 5,02 & 4,49 & 4,49 & 4,19 & 0,39 & 4,55 & 0,52 \\
\hline Relação músculo+gordura/osso & 6,61 & 5,80 & 5,85 & 5,62 & 0,40 & 5,97 & 0,35 \\
\hline
\end{tabular}


tecidos (Tabela 6), resultado atribuído ao grau de desenvolvimento semelhante dos animais, já que todos foram abatidos com o mesmo peso médio. Resultados semelhantes foram observados por Ribeiro et al. (2001) na terminação de bezerros holandeses para produção de vitelos alimentados com $45,60,75$ ou $90 \%$ de concentrado na dieta. Signoretti et al. (1999), estudando níveis de volumoso na dieta $(10,25,40$ ou $55 \%)$ e abatendo bovinos holandeses com 190 e $300 \mathrm{~kg}$ de peso corporal, verificaram maiores conteúdos de gordura para dietas com 10 e $25 \%$ de volumoso. Gesualdi Jr. et al. (2000), estudando a composição física da carcaça de animais F1 Limousin $\times$ Nelore, verificaram que a percentagem de ossos foi afetada pelo nível de concentrado, decrescendo linearmente à medida que aumentou o nível de concentrado na dieta. Brondani et al. (2006) verificaram aumento da percentagem de músculo na carcaça com o incremento de energia na dieta.

As diferenças entre os resultados presentes na literatura para estas características referentes à composição física da carcaça podem estar associadas a diferenças na idade e genótipo dos animais, assim como a diferenças nas características químicas das dietas utilizadas. Segundo Owens et al. (1995), a idade, a condição fisiológica, a condição sexual, o estádio de maturidade, o peso corporal, o nível nutricional, a raça, o estado hormonal e as condições ambientais são os principais fatores que influenciam a taxa de crescimento e a composição física da carcaça. Por outro lado, Berg \& Butterfield (1979) afirmaram que o crescimento do tecido ósseo é maior em idade mais precoce, enquanto o tecido adiposo tem crescimento em idade mais tardia que o tecido muscular, que apresenta desenvolvimento intermediário.

Em relação aos dados obtidos com a análise da carne dos animais, observou-se que a quebra ao descongelamento e ao cozimento não apresentaram variações significativas entre os níveis de concentrado na dieta (Tabela 6). Resultados concordantes foram observados por Brondani et al. (2006), quando avaliaram as carcaças de animais das raças Aberdeen Angus e Hereford submetidos a dois níveis de energia (3,07 e 3,18 Mcal $/ \mathrm{kg}$ de matéria seca) e abatidos com 373,65 kg de peso corporal e 13,5 meses de idade.

Os valores obtidos para a perda de líquidos ao descongelamento foram elevados em comparação aos obtidos no estudo de Brondani et al. (2006) (9,28 vs 2,54\%), o que poderia estar associado à pequena marmorização, a qual não apresentou variação significativa entre os níveis de concentrado na dieta no presente estudo. Segundo Muller (1987), esta é a principal característica que dificulta a perda de líquidos ao descongelamento (Tabela 6).

Os níveis de concentrado da dieta influenciaram $(\mathrm{P}<0,05)$ a coloração da carne (Tabela 6 ), sendo que esta característica apresentou comportamento linear crescente, ou seja, o aumento de concentrado melhorou a coloração da carne, com destaque para os animais alimentados com $79 \%$ de concentrado na dieta, que produziram carne com a máxima classificação quanto à coloração $(5$ pontos $=$ vermelho vivo). Segundo Muller (1987), a cor não influencia algumas características da carne como palatabilidade e características organolépticas, embora seja um fator determinante para a escolha da carne na gôndola pelo consumidor. Os resultados para a coloração da carne estão principalmente associados à diminuição da idade de abate com o aumento do concentrado na dieta, fato evidenciado pela correlação negativa encontrada entre a cor e a idade de abate dos animais $(0,64 ; \mathrm{P}<0,01)$. Esta associação entre a coloração da carne e a idade do animal também foi relatada por Muller (1987), reflexo da maior quantidade, em animais jovens, do pigmento mioglobina (responsável pela cor avermelhada da carne).

Tabela 6 - Características da carne de bovinos alimentados com diferentes níveis de concentrado

\begin{tabular}{|c|c|c|c|c|c|c|c|}
\hline \multirow[t]{2}{*}{ Item } & \multicolumn{4}{|c|}{ Nível de concentrado (\%) } & \multirow[t]{2}{*}{ EP } & \multirow[t]{2}{*}{ Média } & \multirow[t]{2}{*}{$P$} \\
\hline & 22 & 40 & 59 & 79 & & & \\
\hline Quebra ao descongelamento, \% & 8,39 & 7,75 & 10,81 & 10,27 & 1,19 & 9,28 & 0,371 \\
\hline Marmoreio, pontos 1 & 4,50 & 9,25 & 5,50 & 5,25 & 1,31 & 6,12 & 0,101 \\
\hline Cor, pontos 2 & 3,50 & 4,50 & 4,75 & 5,00 & 0,38 & 4,44 & 0,012 \\
\hline Textura, pontos ${ }^{3 \circledR}$ & 3,25 & 3,25 & 4,38 & 4,25 & 0,38 & 3,78 & 0,030 \\
\hline Suculência, pontos 5 & 5,25 & 6,58 & 5,50 & 6,67 & 0,35 & 6,00 & 0,124 \\
\hline Palatabilidade, pontos $^{6}$ & 5,34 & 6,46 & 5,33 & 6,00 & 0,37 & 5,78 & 0,140 \\
\hline
\end{tabular}

${ }^{\circ} \mathrm{Cor}=3,20+0,025 \mathrm{NC}, \mathrm{R}^{2}=0,50$ e CV $=16,50 ;{ }^{\circledR}$ Textura $=2,70+0,022 \mathrm{NC}, \mathrm{R}^{2}=0,53$ e CV $=7,16$.

${ }_{1}$ Marmoreio: 1 a $3=\operatorname{traços} ; 4$ a $6=$ leve; 7 a $9=$ pequeno; 10 a $12=$ médio; 13 a $15=$ moderado; 16 a $18=$ abundante.

2 Cor: 1 = escura; 2 = vermelho escura; 3 = vermelho levemente escura; 4 = vermelho; $5=$ vermelho vivo.

3 Textura: 1 = muito grosseira; 2 = grosseira; 3 = levemente grosseira; 4 = fina; $5=$ muito fina.

${ }^{4}$ Maciez, Suculência e Palatabilidade: 1 = extremamente dura, sem sabor ou; 2 = muito dura, deficiente em sabor ou deficiente em suculência; $3=$ dura, pouco saborosa ou pouco suculenta; 4 = levemente abaixo da média; $5=$ média; $6=$ levemente acima da média; $7=$ macia, saborosa ou suculenta; $8=$ muito macia, muito saborosa ou muito suculenta; $9=$ extremamente macia, extremamente saborosa ou extremamente suculenta. 
A cor é uma das principais características da carne que influencia a compra pelo consumidor, visto que colorações mais escuras inibem a compra, por serem associadas à possível deterioração. A melhora desta característica é importante do ponto de vista dos vendedores finais, como supermercados e açougues, os quais terão maior saída deste produto e consequentemente maior giro de capital.

O incremento de concentrado influenciou positivamente e de forma linear $(\mathrm{P}<0,05)$ a textura da carne, o que foi atribuído à diminuição da idade dos animais ao abate. Segundo Muller (1987), a textura é avaliada por meio da granulação que a superfície do músculo apresenta quando cortada, uma vez que o músculo é constituído por um conjunto de fibras musculares agrupadas em fascíolos envolvidos por uma tênue camada de tecido conectivo, o perimísio. De acordo com este mesmo autor, de modo geral, animais jovens apresentam carne com textura mais fina que a obtida de animais de maior idade.

$\mathrm{O}$ aumento do nível de concentrado na dieta não promoveu $(\mathrm{P}>0,05)$ alterações significativas na maciez da carne, avaliada pelo painel de degustadores e pela força de cisalhamento (Tabela 6). Esta característica da carne é um dos principais fatores que proporciona aos estabelecimentos comerciais fidelizar seu mercado consumidor, já que grande parte dos consumidores busca carne macia, e compram normalmente baseados em experiências passadas. No presente estudo, os valores encontrados para a maciez foram considerados satisfatórios para todos os níveis de concentrado, já que as amostras de carne avaliadas caracterizaram-se como macias e muito macias.

Para a palatabilidade e suculência da carne, da mesma maneira, não se verificou diferenças significativas $(\mathrm{P}>0,05)$ entre os níveis de concentrado (Tabela 6). A pontuação média destas características (5,78 e 6,00, respectivamente) atribuiu à carne notas de palatabilidade e suculência acima da média. Brondani et al. (2006) também não observaram variação na suculência da carne proveniente de animais alimentados com diferentes níveis de energia na dieta. No entanto, observaram correlação negativa entre a palatabilidade e perdas por descongelamento, o que demonstra que perdas maiores de nutrientes no descongelamento podem diminuir a palatabilidade da carne. De outra maneira, Kuss et al. (2005), estudando bovinos abatidos em diferentes pesos, verificaram correlação negativa entre palatabilidade e quebra ao cozimento. Costa et al. (2002) e Restle et al. (1996) associaram ainda as características sensoriais da carne com o grau de marmorização.

\section{Conclusões}

Maiores níveis de concentrado na dieta diminuem a maturidade fisiológica da carcaça e aumentam a participação de cortes nobres na carcaça, diminuindo a textura e melhorando o aspecto visual da carne de bovinos nãocastrados, abatidos aos 14-16 meses de idade, com peso corporal de $400 \mathrm{~kg}$.

\section{Referências}

ANUALPEC - Anuário da pecuária brasileira. 13.ed. São Paulo: Instituto FNP, 2006. 369p.

ASSOCIAÇÃO BRASILEIRA DAS INDÚSTRIAS EXPORTADORAS DE CARNE. Disponível em: <http://www.abiec.com.br/ imprensa> Acesso em: 4/12/2008

BERG, R.T.; BUTTERFIELD, R.M. Nuevos conceptos sobre desarrollo de ganado vacuno. In: El crecimiento del ganado vacuno y la producción de carne de vacuno. Zaragoza: Acribia, 1979. p.16-29.

BRONDANI, I.L.; SAMPAIO, A.A.M.; RESTLE, J. et al. Aspectos quantitativos de carcaças de bovinos de diferentes raças, alimentados com diferentes níveis de energia. Revista Brasileira de Zootecnia, v.33, n.4, p.978-988, 2004.

BRONDANI, I.L.; SAMPAIO, A.A.M.; RESTLE, J. et al. Composição física da carcaça e aspectos qualitativos da carne de bovinos de diferentes raças, alimentados com diferentes níveis de energia. Revista Brasileira de Zootecnia, v.35, n.5, p.2034-2042, 2006.

COSTA, E.C.; RESTLE, J.; VAZ, F.N. et al. Composição física da carcaça, qualidade da carne e conteúdo de colesterol do músculo Longissimus de novilhos Red Angus superprecoce terminados em confinamento, abatidos com diferentes pesos. Revista Brasileira de Zootecnia, v.31, n.1, p.417-428, 2002 (supl.)

COSTA, M.A.L.; VALADARES FILHO, S.C.; PAULINO, M.F. et al. Desempenho, digestibilidade e características de carcaça de novilhos zebuínos alimentados com dietas contendo diferentes níveis de concentrado. Revista Brasileira de Zootecnia, v.34 n.1, p.268-279, 2005.

FERREIRA, M.A.; VALADARES FILHO, S.C.; COELHO DA SILVA, J.F. et al. Consumo, conversão alimentar, ganho de peso e características da carcaça de bovinos F1 Simental x Nelore. Revista Brasileira de Zootecnia, v.28, n.2, p.343-351, 1998

GESUALDI JR., A.G.; PAULINO, M.F.; VALADARES FILHO, S.C. et al. Níveis de concentrado na dieta de novilhos F1 Limousin $x$ Nelore: Características da carcaça. Revista Brasileira de Zootecnia, v.29, n.5, p.1467-1473, 2000.

HANKINS, O.G.; HOWE, P.E. Estimation of the composition of beef carcass and cuts. Washington: Unite State Department of Agriculture, 1946. (Technical Bulletin, 926).

KUSS, F.; RESTLE, J.; BRONDANI, I.L. et al. Composição física da carcaça e qualidade da carne de vacas de descarte de diferentes grupos genéticos terminados em confinamento com distintos pesos. Revista Brasileira de zootecnia, v.34, n.4, p.1285-1296, 2005.

MULLER, L.; MAXON, W.E.; PALMER, A.Z. et al. Evaluación de técnicas para determinar la composición de la canal. In: ALPA, 1973, Guadalajara-México. Anais... Guadalajara: (s.n), 1973.

MULLER, L. Normas para avaliação de carcaças e concurso de novilhos. 2.ed. Santa Maria: Universidade Federal de Santa Maria, 1987. 31p.

NATIONAL RESEARCH COUNCIL - NRC. Nutrients requirements of beef cattle. 7.ed. Washington, D.C.: 1996. 242p.

OWENS, F.N.; GILL, D.R.; SECRIST, D.S. et al. Review of some aspects of growth and development of feedlot cattle. Journal of Animal Science, v.73, p.3152-3172, 1995. 
PACHECO, P.S.; SILVA, J.H.S.; RESTLE, J. et al. Características quantitativas da carcaça de novilhos jovens e superjovens de diferentes grupos genéticos. Revista Brasileira de Zootecnia, v.34, n.5, p.1666-1677, 2005.

PATTERSON, D.C.; STEEN, R.W.; KILPATRICK, D.J. Growth and development in beef cattle. 1. Direct and residual effect of plane of nutrition during early life on components of gain and food efficiency. Journal Agriculture Science, v.124, n.1, p.90-100, 1995.

PETIT, H.V.; VEIRA, D.M.; YU, Y. Growth and carcass characteristics of beef steers fed silage and different levels of energy with or without protein supplementation. Journal of Animal Science, v.52, n.2, p.3221-3229, 1994.

RESTLE, J.; KEPLIN, L.A.S.; VAZ, F.N. et al. Qualidade da carne de novilhos Charolês confinados e abatidos com diferentes pesos. Ciência Rural, v.26, n.3, p.463-466, 1996.

RESTLE, J.; VAZ, F.N.; FEIJÓ, G.L.D. et al. Características de carcaça de bovinos de corte inteiros ou castrados de diferentes composições raciais Charolês e Nelore. Revista Brasileira de Zootecnia, v.29, n.5, p.1371-1379, 2000.

RESTLE, J.; VAZ, F.N.; ALVEZ FILHO, D.C. et al. Efeito da suplementação energética sobre a carcaça de vacas de diferentes idades, terminadas em pastagem cultivada de estação fria sob pastejo horário. Revista Brasileira de Zootecnia, v.30, n.3, p.1076-1083, 2001.
RIBEIRO, T.R.; PEREIRA, J.C.; OLIVEIRA, M.V.M. et al. Carcass characteristics of Holstein veal calves fed diets with different levels of concentrate. Revista Brasileira de Zootecnia, v.30, n.6, p.2154-2162, 2001 (sup1.).

SIGNORETTI, R.D.; SILVA, J.F.C.; VALADARES FILHO, S.C. et al. Composição corporal e exigências líquidas de energia e proteína de bezerros da raça holandesa alimentados com dietas contendo níveis de volumoso. Revista Brasileira de Zootecnia, v.28, n.1, p.195-204, 1999.

SILVA, F.F.; VALADARES FILHO, S.C.; ÍTAVO, L.C.V. et al. Consumo, desempenho, características de carcaça e biometria do trato gastrintestinal e dos órgãos internos de novilhos nelore recebendo dietas com diferentes níveis de concentrado e proteína. Revista Brasileira de Zootecnia, v.31, n.4, p.1849-1864, 2002.

STATISTICAL ANALYSIS SYSTEM - SAS. SAS'S User's guide. SAS for Windows. Cary: SAS Institute Inc., 1997. 46p.

VAZ, F.N.; RESTLE, J.; SILVA, N.L.Q. et al. Nível de concentrado, variedade da silagem de sorgo e grupo genético sobre a qualidade da carcaça e da carne de novilhos confinados, concentrado, variedade da silagem de sorgo. Revista Brasileira de Zootecnia, v.34, n.1, p.239-248, 2005.

WEISS, W.P.; CONRAD, H.R.; ST. PIERRE, N.R. A theoretically based model for predicting total digestible nutrient values of forages and concentrates. Animal Feed Science and Technology, v.39, n.1-2, p.95-110, 1992. 